\title{
Electrochemical Machining of Superhydrophobic Surfaces on Mold Steel Substrates
}

\section{Jinlong Song ${ }^{1,2}$, Wenbo Huang1, Jiyu Liu ${ }^{1}$, Liu Huang1, Yao Lu ${ }^{3 *}$}

${ }^{1}$ Key Laboratory for Precision and Non-traditional Machining Technology of the Ministry of Education, Dalian University of Technology, Dalian 116024, P. R. China.

${ }^{2}$ Collaborative Innovation Center of Major Machine Manufacturing in Liaoning, Dalian University of Technology, Dalian 116024, China.

${ }^{3}$ Nanoengineered Systems Laboratory, UCL Mechanical Engineering, University College London, London, WC1E 7JE, UK.

\section{Corresponding author: Yao Lu. Email: yao.lu@ucl.ac.uk}

Abstract: Superhydrophobic surfaces on mold steel substrates were fabricated via simple and environmentfriendly electrochemical technology followed by fluoroalkylsilane (FAS) modification. The microstructure, crystal structure, chemical composition, and wettability of the sample surfaces were investigated using scanning electron microscopy (SEM), X-ray diffraction (XRD), X-ray photoelectron spectroscopy (XPS), Fourier transform infrared spectroscopy (FTIR) and optical contact angle measuring instrument. The influences of current density and electrochemical machining time on wettability were also studied. The results show that, after the electrochemical processing, the mold steel substrates were covered with a layer of passive films, which have micro/nano binary rough structures composed of rugged plateau structures and rupture-like shapes. Before fluorination, the obtained sample surfaces showed superhydrophilicity (the water contact angles were almost $0^{\circ}$ ), while the sample surfaces became superhydrophobic (the water contact angles were $167.2^{\circ}$ and the water rolling angles were $4.3^{\circ}$ ) after fluorination. The proposed method is simple, economical and environmental- 
friendly, and has great potential for large-scale industrial applications.

Key words: superhydrophobic surface, electrochemical machining, mold steel, passive film.

\section{Introduction}

Superhydrophobic surfaces refer to surfaces whose water contact angles are greater than $150^{\circ}[1]$. On that basis, it can be divided into two types: low adhesive superhydrophobic surfaces (the water rolling angles are lower than $10^{\circ}$ ) and high adhesive superhydrophobic surfaces[2] (the droplets still adhere to the surface even after the surface is turned upside down). To date, superhydrophobic surfaces have attracted researchers' attention and have been widely concerned due to a wide range of applications in self-cleaning[3,4], anti-icing [5,6], fluid drag reduction[7,8], corrosion resistance[9,10], anti-adhesion coating[11], water-oil separation[12,13] and liquid directional transportation[14].

Steel, as a basic alloy, has become the most widely used metal due to its low price, reliable mechanical properties and other excellent characteristics in construction, manufacturing and other industries[15]. It is even considered as material basis of contemporary society[16]. Furthermore, mold steel is one of the most important materials for producing mold products with high precision, high complexity, high consistency and high productivity at a very low cost[17]. With the fast development of steel industry and mold industry, the research on the processing performance of mold steel has become more and more important. Therefore, considering the industrial background of mold steel, fabrication of superhydrophobic coatings on mold steel has considerable industrial significance.

The fabrication of superhydrophobic surfaces is achieved in two key steps: the preparation of micro/nano binary rough structures and low surface energy modification. At present, numerous methods have been 
developed to fabricate superhydrophobic surfaces. However, the metal substrates are limited in aluminum, titanium, copper, and the research on other metal materials especially steel substrates is still inadequate. Chen et al. [18]firstly pre-treated the stainless substrate with $200 \mu \mathrm{m}$ silicon dioxide and then immersed the substrate in plating bath solution for $4 \mathrm{~h}$ at $80^{\circ} \mathrm{C}$ to prepare nanoscale Ni layer, and successfully obtained superhydrophobic surfaces with a contact angle of $150^{\circ}$ after low surface energy modification; Tan et al.[19] plated nickel surface on steel via electro-deposition nickel process, followed by stearic acid modification. The superhydrophobic surface on steel substrate was obtained, with a water contact angle of $154.4^{\circ}$. A widely used approach of coating nanoparticles on the surface was applied due to its low cost. Li et al. [20] used hydrofluoric acid solution to etch stainless 304 SS and 316 SS, and immersed the steels in 50\% nitric acid solution after rinsing the etched steels with deionized water. Water contact angles of the prepared surfaces on $304 \mathrm{SS}$ and $316 \mathrm{SS}$ substrates were $159.9^{\circ}$ and $146.6^{\circ}$, respectively; Gao et al. [21] immersed GCr15 steel substrate in $10 \mathrm{v} \%$ sulfuric acid solutions added with $\mathrm{H}_{2} \mathrm{O}_{2}$ for $1 \mathrm{~h}$ and soaked samples in $0.5 \mathrm{v} \%$ FAS-13 in ethyl alcohol at $70{ }^{\circ} \mathrm{C}$ for $12 \mathrm{~h}$, followed by dried in vacuum. The superhydrophobic GCr15 surface was obtained via chemical etching, followed by modification, with a water contact angle of $163.5^{\circ}$; Choi et al.[22] used $\mathrm{HNO}_{3}$ as the electrolyte and set up a three-electrode system for fabricating micro/nano binary rough structures of rounded grain shapes on SS 316 substrates via common metallographic technique of grain boundary etching[23] which is accompanied with polarization. The superhydrophobic SS 316 substrates were obtained, with a contact angle of $163.9^{\circ} \pm 1.2^{\circ}$ and a roll-off angle of $10.7^{\circ} \pm 1.8^{\circ}$, respectively. However, due to the use of strong acids, the aforementioned methods will put pressure on the environment and bring higher production cost to the process. Wu et al. [24] irradiated stainless substrates with femtosecond laser pulses, fabricating typical laser-induced periodic microstructures to obtain superhydrophobic surfaces, with a contact angle of $166.3^{\circ}$ and a rolling angle of $4.2^{\circ}$. However, machining process such as laser machining is relatively complicated and expensive due to its high requirements of equipment and energy consumption. 
Therefore, it is significant to propose a simple, high efficient, low cost and environmental-friendly method to fabricate superhydrophobic surfaces on steel substrates.

Electrochemical machining (ECM) technology has been widely used in various process of industrial production[25]. ECM is an effective way to fabricate micro/nano binary rough structures which is necessary to superhydrophobic surfaces. Indeed, ECM technology is simply, fast, and very reproducible. Moreover, it includes anode oxidation processing, electrochemical etching, electrochemical deposition and others, therefore, it is able to create a large variety of surface morphologies including fibers, tubes, needles, sheets and others[26]. We demonstrated that ECM was used to create surface structures with roughness on $\mathrm{Zn}$ [27] and Mg alloy surfaces [28] to achieve superhydrophobicity. The processing of anode oxidation and electrochemical etching occurred, respectively.

In this paper, a simple method was proposed to prepare superhydrophobic surfaces on mold steel substrate via ECM based on passivation property of steel. We used the mold steel as anode, and formed the passive films on its surface via ECM, so that the micro/nano binary rough structures can be created. After reduction of surface energy of the passive films, superhydrophobic surfaces were obtained. The proposed method was low cost, simple and environmental-friendly.

\section{Experimental}

\subsection{Materials}

Anode material: $\Phi 24 \mathrm{~mm} \times 5$ mm GCr15 mold steel plate (from Shenzhen An FENG Company);

Cathode material: $\Phi 20 \mathrm{~mm} \times 90 \mathrm{~mm}$ brass rod (from Shenzhen An FENG Company); Anhydrous alcohol and $\mathrm{NaNO}_{3}$ were purchased from Beijing Chemical Factory; 
FAS [tridecafluoroctyltriethoxysilane, $\mathrm{C}_{8} \mathrm{~F}_{13} \mathrm{H}_{4} \mathrm{Si}\left(\mathrm{OCH}_{2} \mathrm{CH}_{3}\right)_{3}$ ]: 95\% purity from Degussa Company

2.2 Fabrication of superhydrophobic surfaces

During the electrochemical machining process, the bubbles produced by the products of electrolysis and the liquid pump will affect the conductivity distribution of the electrolyte in process[29]. In order to guarantee that the electrolyte was kept at a certain velocity the state of which must be turbulent[30], considering the characteristics of the workpiece, we designed a special fixture made by nylon material to obtain lateral flowing electrolyte. Furthermore, large area electrochemical machining can be realized by tuning the size of the fixture.

Fig. 1 shows the scheme of electrochemical machining system, electrolyte flow, electrical control system and the fixture.

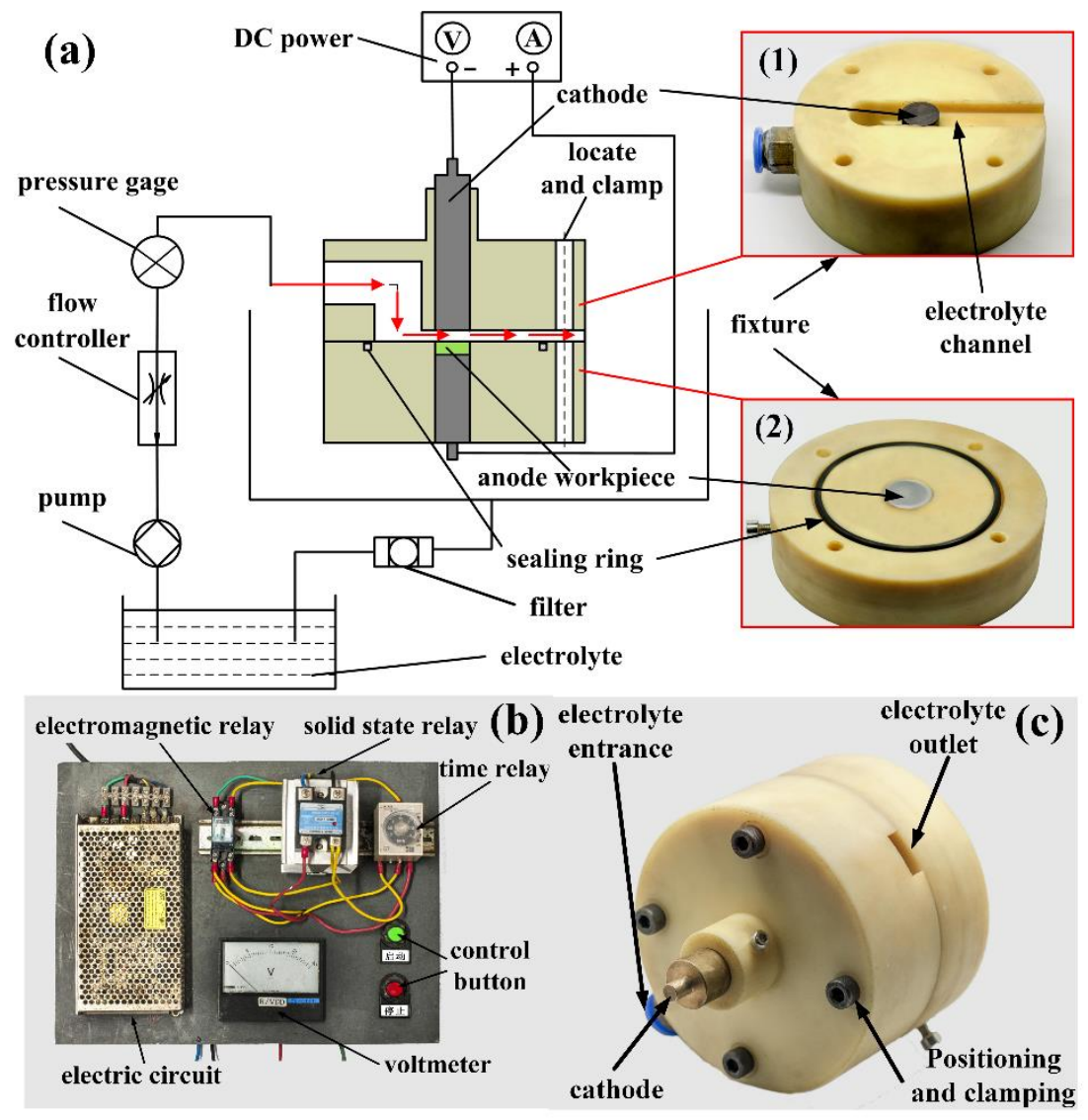

Fig. 1 Scheme of ECM system. (a) Electrolyte flow; (b) electrical control system; (c) fixture 
The surface of the cathode brass was polished using 400\#, 800\#, 1500\#, 2000\# metallographic abrasive papers on metallographic polisher and then put into the special fixture, as shown in Fig. 1 (a). Prior to electrochemical machining, the mold steel (GCr15) substrates were polished using 400\#, 800\#, 1500\#, 2000\# metallographic abrasive paper on metallographic polisher, and then ultrasonically cleaned by water and anhydrous ethanol to remove the impurities and the oxidelhydroxide layer on the surfaces. After drying by compressed air, the mold steel samples were put into a special fixture as shown in Fig. 1 (a).

ECM system mainly consists of the following parts: the power section with constant-current and stabilizedvoltage supply to ensure a constant current density; the electric control part of the time relay to precisely control the electrochemical machining time [Fig. 1 (b)]; the electrochemical reaction section using the special fixture to achieve lateral flowing electrolyte [Fig. 1 (c)]; the electrolyte flow control system for precise control of electrolyte; and the electrolyte circulatory system that is composed of three-grade-filtration to remove the waste from electrochemical machining for preventing the influence of produced waste.

Under the parameters of the electrochemical machining as shown in Table 1, passive films composed of micro/nanometer-scale binary rough structures can be fabricated.

Table. 1 Processing parameters of ECM

\begin{tabular}{cc}
\hline Parameters of ECM & Number \\
\hline Electrolyte concentration & $25 \%(\mathrm{wt} \%) \mathrm{NaNO}_{3}$ \\
Electrolyte flow $\boldsymbol{q} / \mathbf{L} \cdot \mathbf{h}^{-1}$ & 120 \\
Processing time $\boldsymbol{t} / \mathbf{s}$ & $2 \sim 120$ \\
Current density $\boldsymbol{i} / \mathbf{A} \cdot \mathbf{c m}^{-2}$ & $2 \sim 9$ \\
Inter-electrode gap $\boldsymbol{h} / \mathbf{m m}$ & 0.5 \\
\hline
\end{tabular}

When the time relay control system stopped running, suggesting that the electrochemical machining process was over, the workpiece material was removed from the fixture and cleaned with deionized water for $2 \sim 3$ times. 
After dried by compressed air, the samples were immersed into $1 \mathrm{wt} \%$ FAS ethanol solution for 1 hour followed by dried at $80{ }^{\circ} \mathrm{C}$ for $20 \mathrm{~min}$.

\subsection{Sample Characterization}

The wettability including water contact angles (CA) and water rolling angles (RA) were measured using an optical contact angle measurement (krüss, DSA100, German) and self-made rolling angle measuring instrument at room temperature. The water volumes that were used in contact angle and rolling angle measurements were $5 \mu \mathrm{L}$ and $10 \mu \mathrm{L}$, respectively. The surface micro/nano-scaled morphologies were investigated via a scanning electron microscope (SEM, JSM-6360LV, Japan). The chemical compositions were characterized using X-ray photoelectron spectroscopy (XPS, Thermo, ESCALAB-150Xi, America) and Fourier transform infrared spectroscopy (FTIR, JASCO, Japan). The crystal structure was analyzed via X-ray diffraction system (XRD6000, Japan).

\section{Results and discussion}

3.1 The influence of current density on wettability and morphologies

3.1.1 The morphologies and chemical compositions of the sample surfaces

Fig. 2 (a) shows the SEM images of passive film morphologies formed on GCr15 mold steel at different current densities after $90 \mathrm{~s}$ electrochemical machining process. As shown in Fig. $2\left(\mathrm{a}_{1}\right)$, there were only a few scratches on the untreated sample surface. By contrast, there were many rugged plateau structures and wellproportioned micron particles and a few nano-scaled particles on the surface of passive films when current density $i=2 \mathrm{~A} \cdot \mathrm{cm}^{-2}$, as shown in Fig. $2\left(\mathrm{a}_{2}\right)$. When the current density increased $\left(i=5 \mathrm{~A} \cdot \mathrm{cm}^{-2}\right)$, the micron 
particles on the surface of passive films were broken, forming sub-micron and nano-scaled rupture-like particles, and we could then obtain the micro/nano-scaled binary rough structures as shown in Fig. 2 (a). When the current density increased to $9 \mathrm{~A} \cdot \mathrm{cm}^{-2}$, the electrochemical action was so strong that micron particles were massively broken, therefore there were mainly nano-scaled particles on the surfaces as shown in Fig. 2 (a4). Fig. 2 (b) shows XRD pattern of GCr15 surface before and after ECM. The diffraction peak was mainly formed by $\alpha-\mathrm{Fe}$, indicating that $\mathrm{GCr} 15$ was almost composed of polycrystalline ferrite and main crystal structures were unchanged after ECM. Fig. 2 (c) shows the XPS spectrum of GCr15 with passive film after ECM $\left(i=5 \mathrm{~A} \cdot \mathrm{cm}^{-}\right.$ ${ }^{2}, t=90 \mathrm{~s}$ ). Combined with Table. 2 , the results indicate that $\mathrm{Fe}$ of passive film was mainly in the form of Fe[II] and $\mathrm{Fe}[\mathrm{III}]$, and that a certain amount of $\mathrm{Cr}$ was in the form of $\mathrm{Cr}[\mathrm{II}]$ and $\mathrm{Cr}[\mathrm{III}]$, with few $\mathrm{Cr}[\mathrm{VI}][31]$. Table. 2 shows chemical compositions of GCr15 surfaces before and after ECM according to XPS spectrum. Compared with original GCr15, the content of $\mathrm{C}$ increased greatly and a large amount of $\mathrm{O}$ appeared, suggesting that the forming process of passive films was accompanied by carburizing and oxidation filled with Fe and Cr. Fig. 2 (d) shows the FTIR spectra of sample surfaces before and after FAS modification. $1374 \mathrm{~cm}^{-1}, 1242 \mathrm{~cm}^{-1}$, $1197 \mathrm{~cm}^{-1}, 1143 \mathrm{~cm}^{-1}$, were assigned to the $\mathrm{C}-\mathrm{F}$ stretching vibration of the $-\mathrm{CF}_{2}-$ and $-\mathrm{CF}_{3}-$ groups of the FAS molecules[28]. $1089 \mathrm{~cm}^{-1}$ can be explained by the asymmetric stretching of newly reacted Si-O-Si bonds[32].

The results of FTIR confirmed that the FAS had been successfully treated on passive films, and that the modified surface was under the state of low surface energy with micro/nano-scaled binary rough structures. As a result, the superhydrophilic sample surfaces became superhydrophobic. Fig. 2 (e) shows that the untreated GCr15 surfaces were silvery white, while the surfaces of GCr15 with passive film were dark gray or black after ECM. 
(a1) $0 \mathrm{~A} \cdot \mathrm{cm}^{-2}$

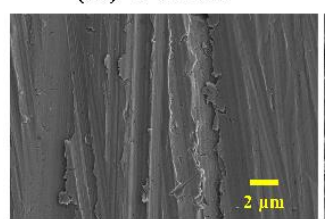

(a) $5 \mathrm{~A} \cdot \mathrm{cm}^{-2}$

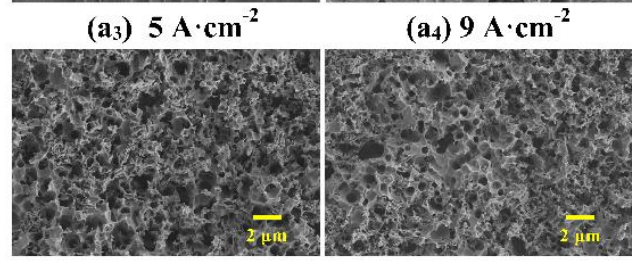

(a) $2 \mathbf{A} \cdot \mathrm{cm}^{-2}$

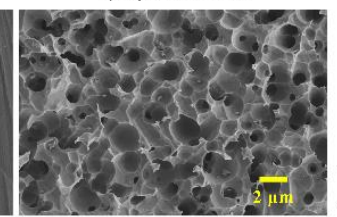

(a4) $9 \mathrm{~A} \cdot \mathrm{cm}^{-2}$

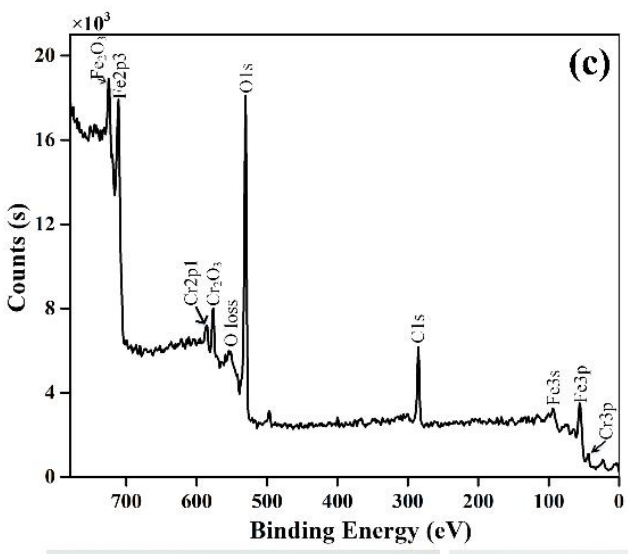

$\left(e_{1}\right)$

$\left(\mathbf{e}_{2}\right)$
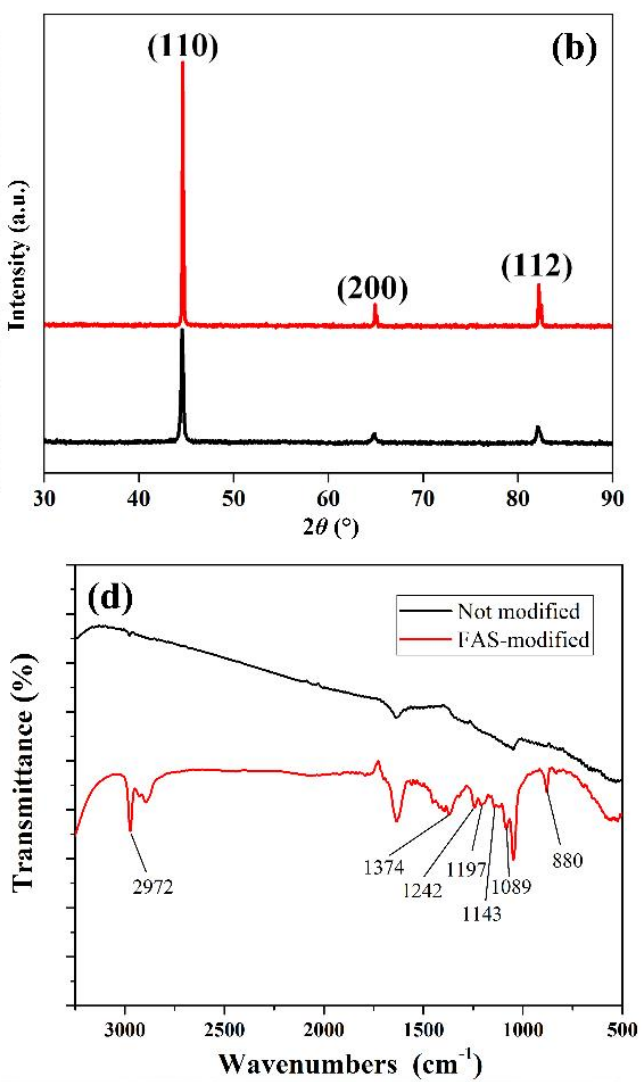

$\left(\mathbf{e}_{3}\right)$
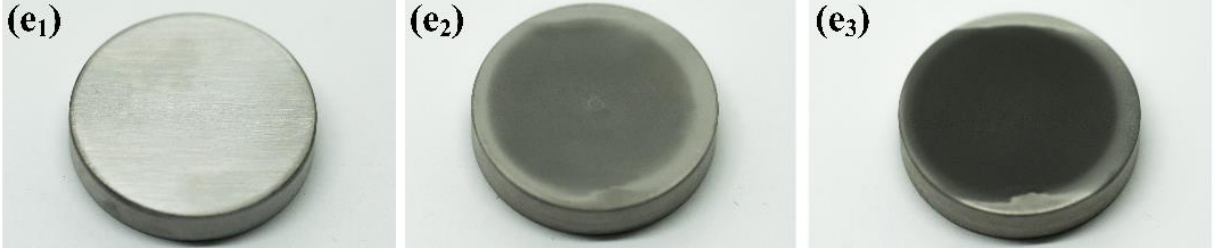

Fig. 2 Surface morphology, crystal structure and chemical composition. (a) SEM images of passive film morphology formed at different current densities $(t=90 \mathrm{~s})$; (b) XRD patterns of GCr15 surface before (bottom) and after (top) ECM; (c) XPS spectrum of passive film on GCr15 surface after ECM; (d) FTIR spectra of GCr15 surfaces before and after ECM; (e) Optical images of passive films formed at different current densities $(t=90 \mathrm{~s})$ : (a) $i=0 \mathrm{~A} \cdot \mathrm{cm}^{-2}$; (b) $i=2 \mathrm{~A} \cdot \mathrm{cm}^{-2}$; (c) $i=5 \mathrm{~A} \cdot \mathrm{cm}^{-2}$

Table. 2 The element composition of GCr15 surfaces before (top) and after ECM (bottom) via XPS analysis

\begin{tabular}{ccccc}
\hline Name & C1s & Fe2p & O1s & Cr2p \\
\hline Atomic (\%) & 20.76 & 64.87 & 0 & 13.51 \\
Atomic (\%) & 29.48 & 19.53 & 46.8 & 4.18 \\
\hline
\end{tabular}


3.1.2 Wettability of the mold steel GCr15 surfaces

Fig. 3 shows the images of water contact angles on original GCr15 surfaces before and after FAS modification. The water contact angle was about $80.5^{\circ}$ on original GCr15 surface, showing hydrophilicity because of its high surface energy [Fig. 3 (a)]. The water contact angle on original GCr15 surfaces after FAS modification was 107. $2^{\circ}$, showing hydrophobicity [Fig. 3 (b)]. This is because the structure of fluoroalkylsilane includes one $\mathrm{CF}_{3}$ group with $6.7 \mathrm{~mJ} / \mathrm{m}^{2}$ surface energy and five $-\mathrm{CF}_{2}-$ groups with $18 \mathrm{~mJ} / \mathrm{m}^{2}$ surface energy[33]. So that the FAS has low surface energy and does not change the microstructures of the surface in the process of low surface energy modification. The comparison results clearly demonstrates the effect of low surface energy modification using FAS. However, the modified surface was still not superhydrophobic due to the lack of rough micro/nano structures[34].

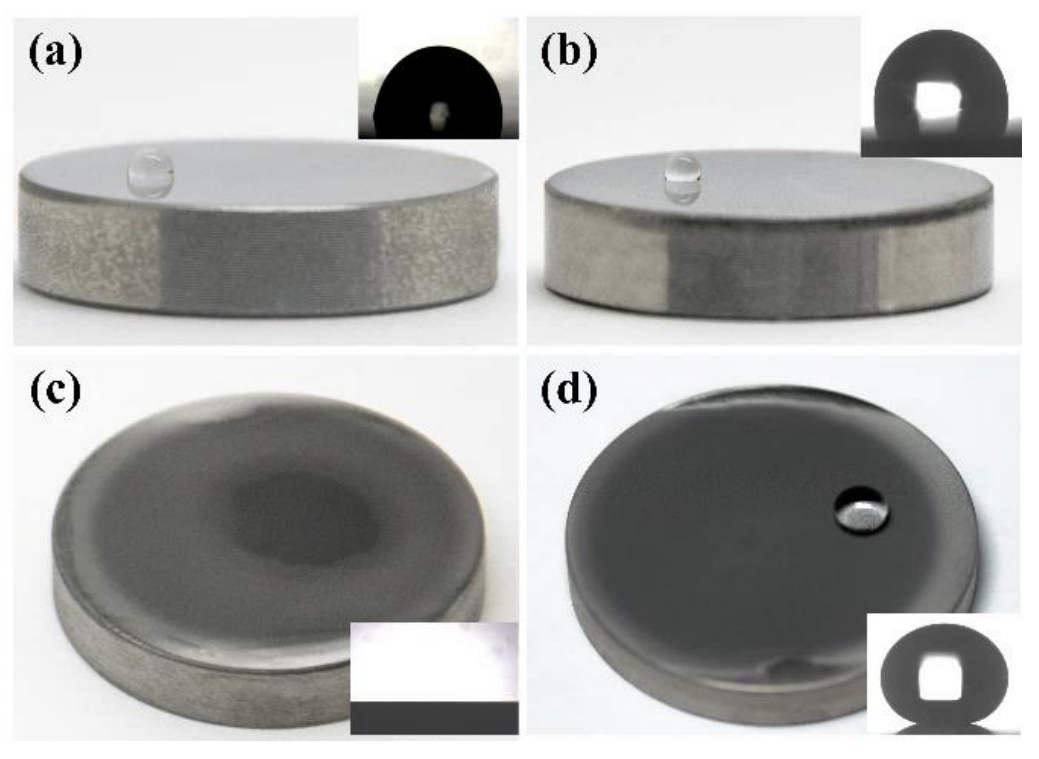

Fig. 3 The optical images of the water droplets on original mold steel surfaces before (a) and after (b) FAS modification without ECM process; and water droplets on mold steel surfaces with passive films (after ECM) before (c) and after (d) FAS modification. 
Fig. 3 (c) and (d) shows the optical images of the water contact angles on GCr15 surfaces with passive films obtained by ECM $\left(i=5 \mathrm{~A} \cdot \mathrm{cm}^{-2}, t=90 \mathrm{~s}\right)$ before and after FAS modification. The machined surfaces before FAS modification shows superhydrophilicity, and water droplets spread rapidly on the surfaces [Fig. 3 (c)]. On the basis of Wenzel's theory[35], roughening a surface enhances its hydrophilicity, resulting in the hydrophilic GCr15 surfaces to become superhydrophilic[36]. However, after FAS modification, superhydrophilic GCr15 surfaces were transformed into superhydrophobic surfaces, with the water contact angle and rolling angle being $167.2^{\circ}$ and $4.4^{\circ}$, respectively [Fig. 3 (d)]. Therefore, the preparation of passive films with micro/nano binary rough structures by electrochemical machining and the low surface energy modification via FAS treatment were necessary to fabricate superhydrophobic surfaces. On a superhydrophobic surface, water droplet was supported by both solid surface structures and air-pockets in the Cassie-Baxter state[37]. The equation of the contact angle is described as follows

$$
\cos \theta_{c}=f_{1}\left(\gamma_{S G}-\gamma_{S L}\right) / \gamma_{L G}-f_{2}=f_{1} \cos \theta-f_{2}
$$

Where $\theta_{c}$ and $\theta$ represent the contact angles on the rough and smooth surfaces after FAS modification; $f_{1}$ and $f_{2}$ are the area fractions of solid and air on the surface. In this case, $\theta_{c}=167.2^{\circ}, \theta=107.2^{\circ}$ and $f_{1}+f_{2}=1$, Therefore, according to Equation (1), when a water droplet was put on the surface, only $4.12 \%$ of apparent area contacted with the solid surface, and $95.88 \%$ of the area only contacted with air.

Fig. 4 (a) and (b) shows the influence of the current density in electrochemical machining on the wettability of mold steel GCr15 surfaces with passive films (all samples were treated with FAS before contact angle and sliding angle measurements). When the current density was relatively smaller $\left(i<4 \mathrm{~A} \cdot \mathrm{cm}^{-2}\right)$, the water contact angles increased obviously, but water droplets still could not roll off, which indicates that the surfaces were still highly adhesive to water. While the current density $i=4 \mathrm{~A} \cdot \mathrm{cm}^{-2}$, low adhesive superhydrophobic surfaces could be prepared, the water contact angle was $165.3^{\circ}$ and the water rolling angle was $9.2^{\circ}$. Better 
superhydrophobicity can be achieved when current density $i=5 \mathrm{~A} \cdot \mathrm{cm}^{-2}$, the water contact angle was $167.2^{\circ}$ and the water rolling angle was $4.4^{\circ}$.

According to the SEM images and pictures of mold steel GCr15, the original surface was silvery white [Fig. $4\left(\mathrm{c}_{1}\right)$ ], and there were just some scratch traces on the surface [Fig. $4\left(\mathrm{~d}_{1}\right)$ ]. When the current density $i=$ $2 \mathrm{~A} \cdot \mathrm{cm}^{-2}$, the surface became gray white [Fig. $\left.4\left(\mathrm{c}_{2}\right)\right]$, with some microstructures on it [Fig. $\left.4\left(\mathrm{~d}_{2}\right)\right]$. When the current density increased to $3 \mathrm{~A} \cdot \mathrm{cm}^{-2}$, the treated surface was still gray white [Fig. $4\left(\mathrm{c}_{3}\right)$ ], but some microstructures were ruptured and some nanostructures appeared [Fig. $4\left(\mathrm{~d}_{3}\right)$ ], causing the surfaces to be more superhydrophobic. When the current density $i \geqslant 4 \mathrm{~A} \cdot \mathrm{cm}^{-2}$, the surfaces became black dark [Fig. $\left.4\left(\mathrm{c}_{4}\right)-\left(\mathrm{c}_{9}\right)\right]$, because the reaction was so strong that the anodic corrosion speeded up, and $\mathrm{C}$ deposited on the anode; meanwhile, the microstructures were continuously broken up to form more nanostructures, thereby forming micro/nano-scaled binary rough structures [Fig. $\left.4\left(\mathrm{~d}_{4}\right)-\left(\mathrm{d}_{9}\right)\right]$. As a result, the surface hydrophobicity was improved[38]. 

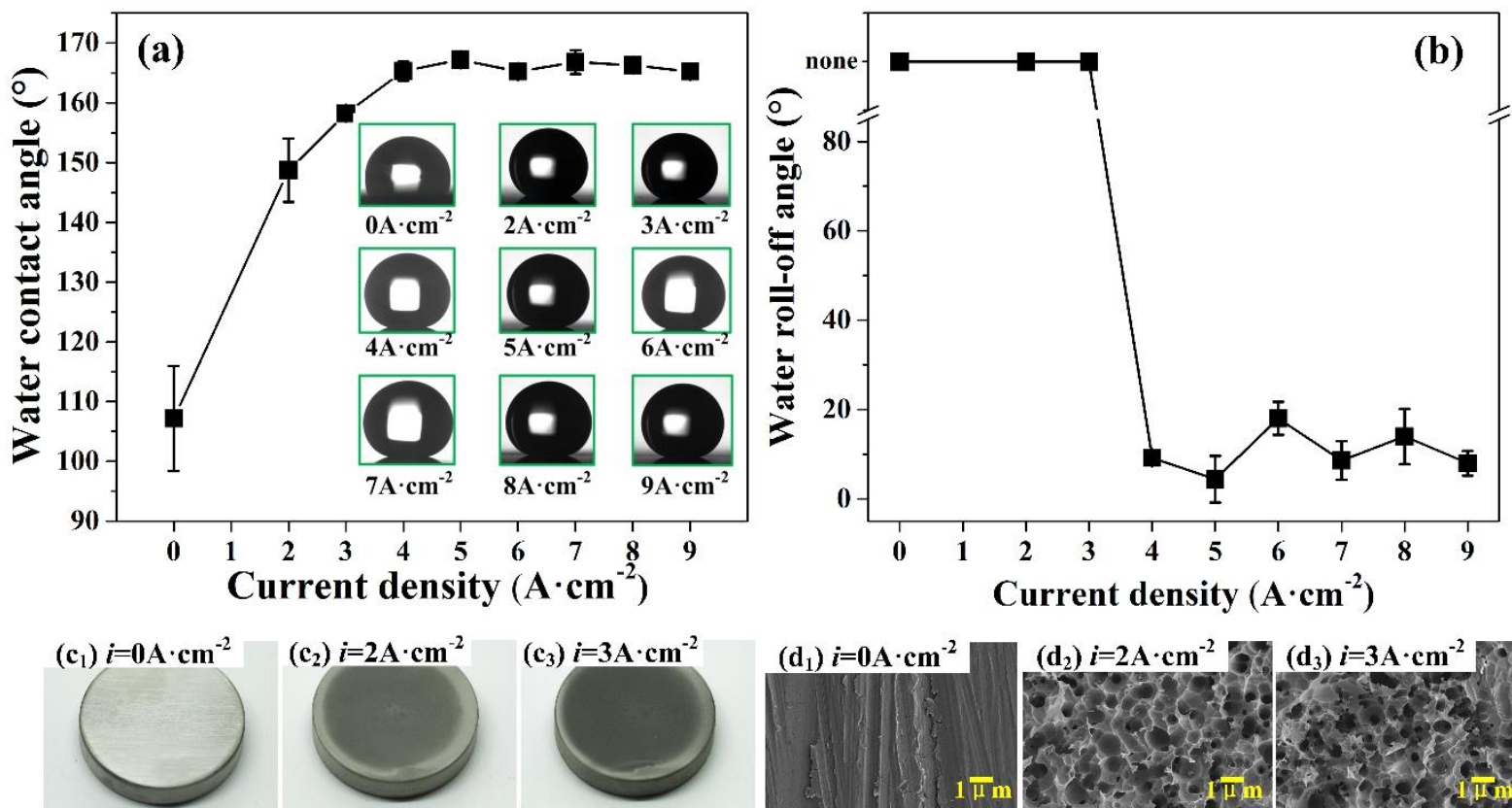

(c $\left.c_{2}\right)=2 \mathrm{~A} \cdot \mathrm{cm}^{-2}$

(c $\left.c_{3}\right) i=3 \mathrm{~A} \cdot \mathrm{cm}^{-2}$
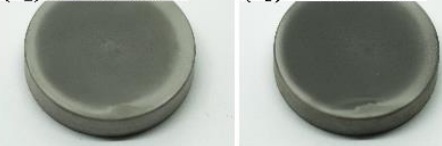

(d $\left.{ }_{1}\right)=0 \mathrm{~A} \cdot \mathrm{cm}^{-2}$

( $\left.\mathrm{c}_{4}\right) i=\mathbf{4 A} \cdot \mathrm{cm}^{-2}$

(c) $i=5 \mathrm{~A} \cdot \mathrm{cm}^{-2}$

(c) $i=6 \mathrm{~A} \cdot \mathrm{cm}^{-2}$
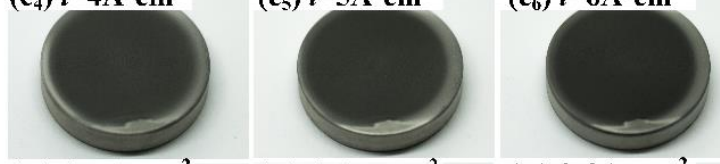

$\left(\mathrm{c}_{7}\right) i=7 \mathrm{~A} \cdot \mathrm{cm}^{-2}$

(c) $i=\mathbf{8 A} \cdot \mathrm{cm}^{-2}$

(c) $i=9 \mathrm{~A} \cdot \mathrm{cm}^{-2}$
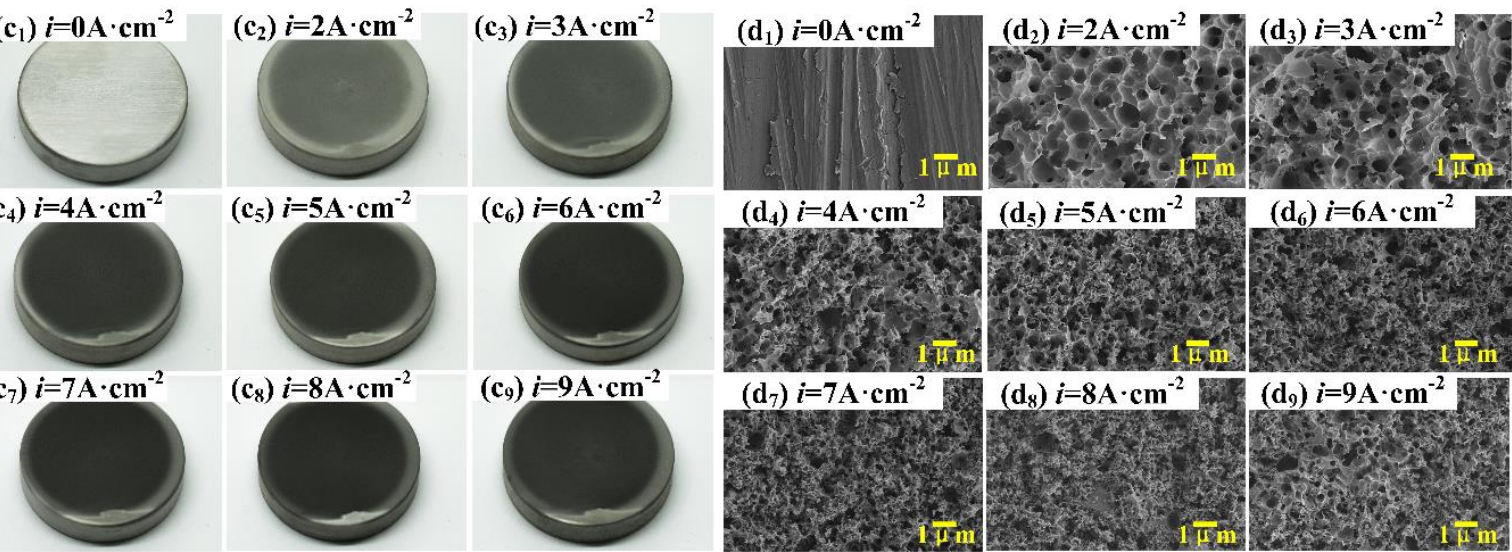

(d) $i=5 \mathrm{~A} \cdot \mathrm{cm}^{-2}$

(d $) i=6 \mathrm{~A} \cdot \mathrm{cm}^{-2}$

$\left(\mathrm{d}_{7}\right) i=7 \mathrm{~A} \cdot \mathrm{cm}^{-2}$
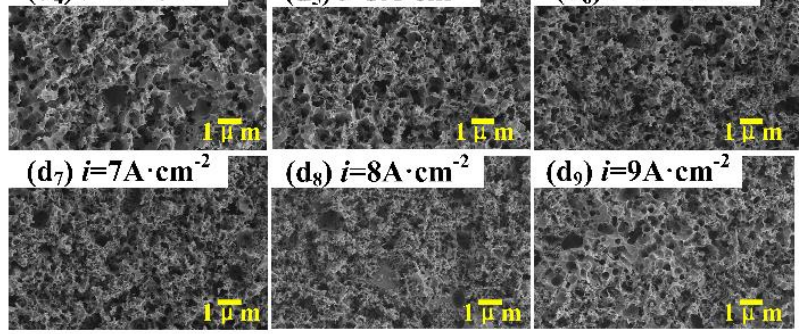

(d $) i=8 \mathrm{~A} \cdot \mathrm{cm}^{-2}$

$\left(\mathrm{d}_{9}\right) i=9 \mathrm{~A} \cdot \mathrm{cm}^{-2}$

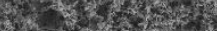

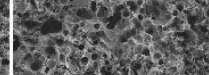

314.

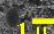

Fig. 4 Wettability and surface morphology of superhydrophobic GCr15 mold steel. (a) (b) The influence of the current density in ECM processing on the wettability on passive films formed on GCr15 surfaces; (c) Optical images of passive films formed at different current densities $(t=90 \mathrm{~s})$;(d) SEM images of passive film morphology formed at different current densities $(t=90 \mathrm{~s})$

3.2 The influence of ECM processing time on surface wettability and morphologies

Fig. 5 (c) and (d) shows the influence of processing time $(2 \mathrm{~s}, 5 \mathrm{~s}, 10 \mathrm{~s}, 20 \mathrm{~s}, 40 \mathrm{~s}, 60 \mathrm{~s}, 90 \mathrm{~s}, 120 \mathrm{~s})$ on the wettability of mold steel GCr15 surfaces with passive films (all samples were treated with FAS before contact angle and sliding angle measurements). When the processing time $t<20 \mathrm{~s}$, with the time increasing, the water contact angles became larger and larger, and the water rolling angles obviously decreased. However, when the processing time $t>20 \mathrm{~s}$, the water contact angles and rolling angles did not significantly change with the 
increase of the processing time. As shown in Fig. 5 (c) and (d), the superhydrophobic surface could be obtained after only $2 \mathrm{~s}$ ECM, with water contact angle and rolling angle being respectively $152.8^{\circ}$ and $27.2^{\circ}$. Additionally, the relatively optimum hydrophobicitiy was achieved when processing time $t=90 \mathrm{~s}$, with the water contact angles of $167.2^{\circ}$ and the water rolling angles of $4.4^{\circ}$. Compared with the innovative method of grain boundary etching for fabricating superhydrophobic surface on stainless 316 [22], superhydrophobicity was achieved with a higher contact angle and a smaller rolling angle.

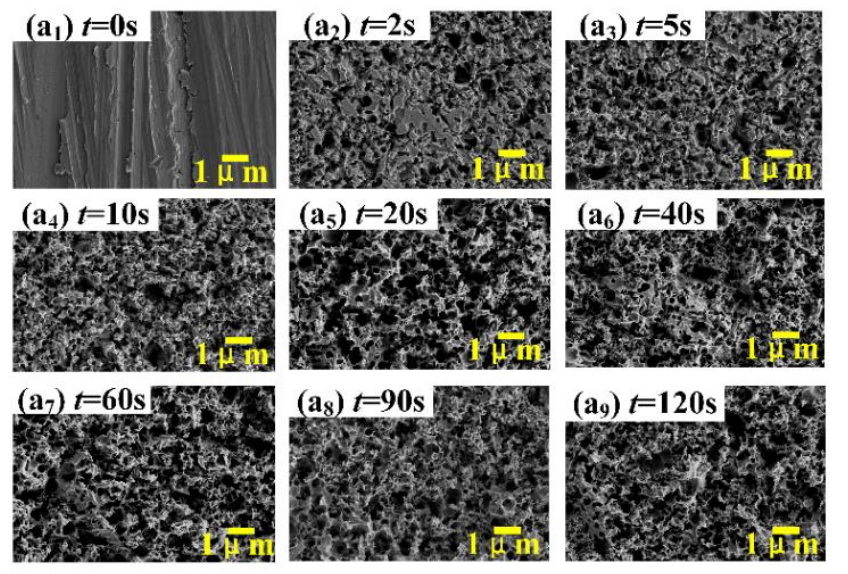

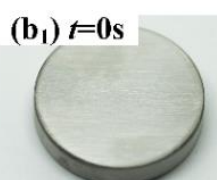

(b4) $t=10 \mathrm{~s}$

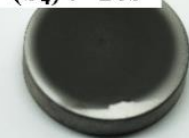

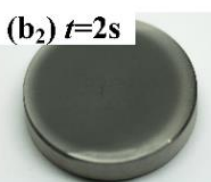

(b5) $t=20 \mathrm{~s}$

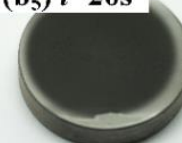

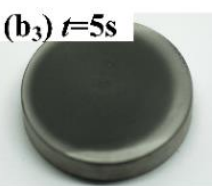

( $\left.\mathrm{b}_{6}\right) t=40 \mathrm{~s}$
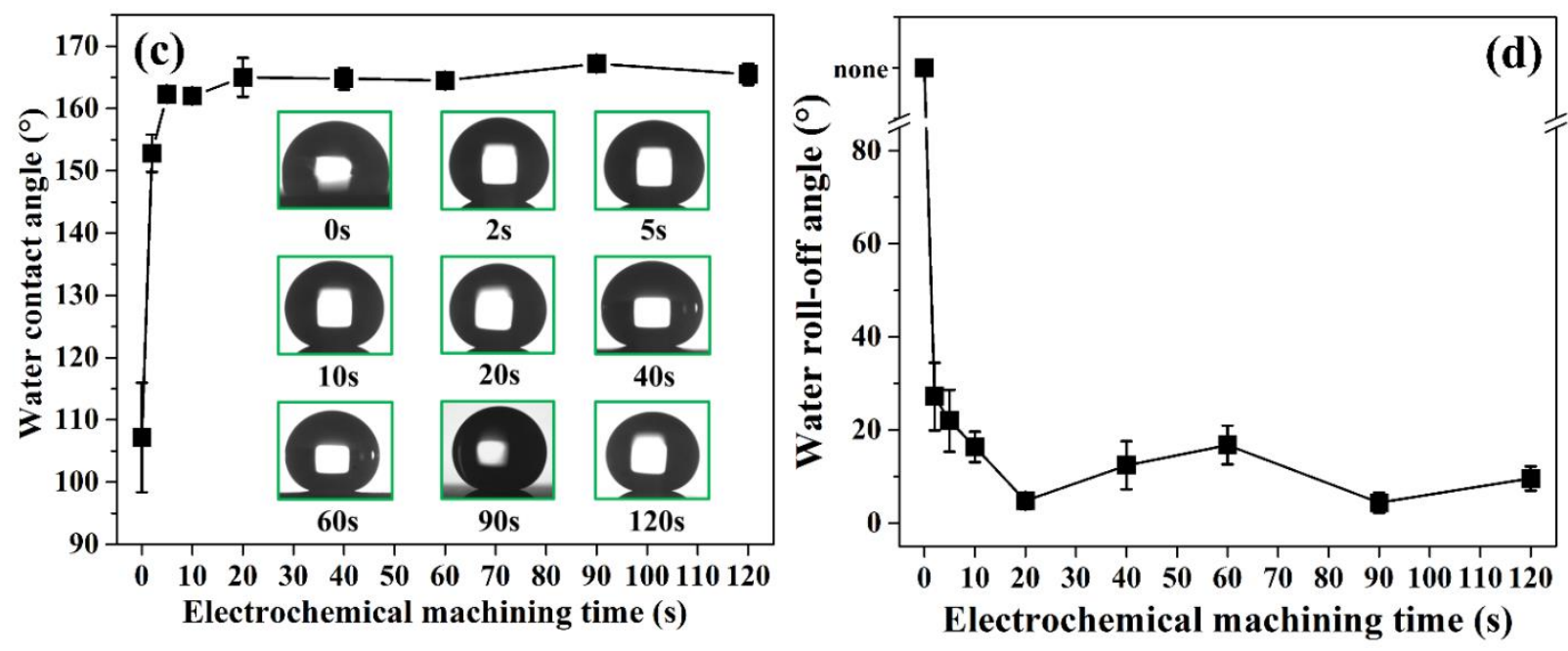

(d)

(b) $t=60 \mathrm{~s}$

$\left(\mathrm{b}_{8}\right) t=90 \mathrm{~s}$

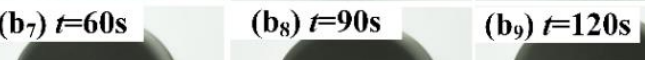

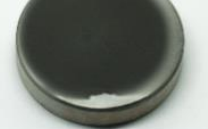

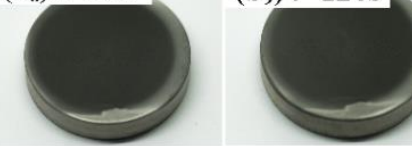

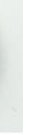
(1) 
Fig. 5 (a) shows the SEM images of mold steel GCr15 surfaces under $5 \mathrm{~A} \cdot \mathrm{cm}^{-2}$ current density with different electrochemical machining times $(0 \mathrm{~s}, 2 \mathrm{~s}, 5 \mathrm{~s}, 10 \mathrm{~s}, 20 \mathrm{~s}, 40 \mathrm{~s}, 60 \mathrm{~s}, 90 \mathrm{~s}, 120 \mathrm{~s})$. As shown in Fig. 5 (a $)$, common sample surfaces only had some polished scratch traces. When the processing time $t=2 \mathrm{~s}$, the structures were mainly composed of microscale plateau-like shapes, with a few nanoscale concaves [Fig. $\left.5\left(\mathrm{a}_{2}\right)\right]$. When the processing time $t=5 \mathrm{~s}$, the plateau-like shape microstructures were broken down, thus forming the micro/nano-scaled binary rough structures [Fig. $5\left(\mathrm{a}_{3}\right)$ ]. With time increasing, the quantity and the degree of the rupture-like structures also increased, thereby forming the micro/nano-scaled structures that were necessary to achieve superhydrophobicity [Fig. 5 (a4)-(a9)]. Fig. 5 (b) shows optical images of the passive films that formed at different processing times under the current density of $i=5 \mathrm{~A} \cdot \mathrm{cm}^{-2}$. Common surfaces were silver white [Fig. $5\left(b_{1}\right)$ ], while the sample surfaces after ECM process became dark grey [Fig. $5\left(b_{2}\right)$ ] and even black [Fig. $5\left(b_{3}\right)$ (b)].

3.3 Analysis of the reason for formation of micro/nano rough structures

In this experiment, we employed electrochemical machining method to obtain the micro/nano structures. During the electrochemical machining process, GCr15 surface was covered with the passive film, which is dense, highly adhesive to water and protective[39]. At present, the correlation analysis of the formation of the passive film is mainly composed of phase-formation theory [40] and adsorption theory[41]. The passive film is generally considered to be composed of two or more layers of compound films[42]. Fig. 6 shows the forming process of the passive films on GCr15 surface, where M represented Fe and Cr. The chemical reactions in this process were as follows.

$$
\begin{array}{cr}
\mathrm{O}_{2}+\mathrm{H}_{2} \mathrm{O}+\mathrm{e}^{-} \rightarrow \mathrm{OH}^{-} & \text {Reaction 1 } \\
\mathrm{M}^{2+}+\mathrm{H}_{2} \mathrm{O} \rightarrow \mathrm{M}(\mathrm{OH})_{2}+\mathrm{H}^{+} & \text {Reaction 2 }
\end{array}
$$




$$
\mathrm{MO}+\mathrm{H}_{2} \mathrm{O}+\mathrm{OH}^{-} \rightarrow \mathrm{MOOH}+\mathrm{e}^{-}
$$

$$
\mathrm{M}^{3+}+\mathrm{O}_{2}+\mathrm{e}^{-} \rightarrow \mathrm{M}_{2} \mathrm{O}_{3}
$$

Reaction 4

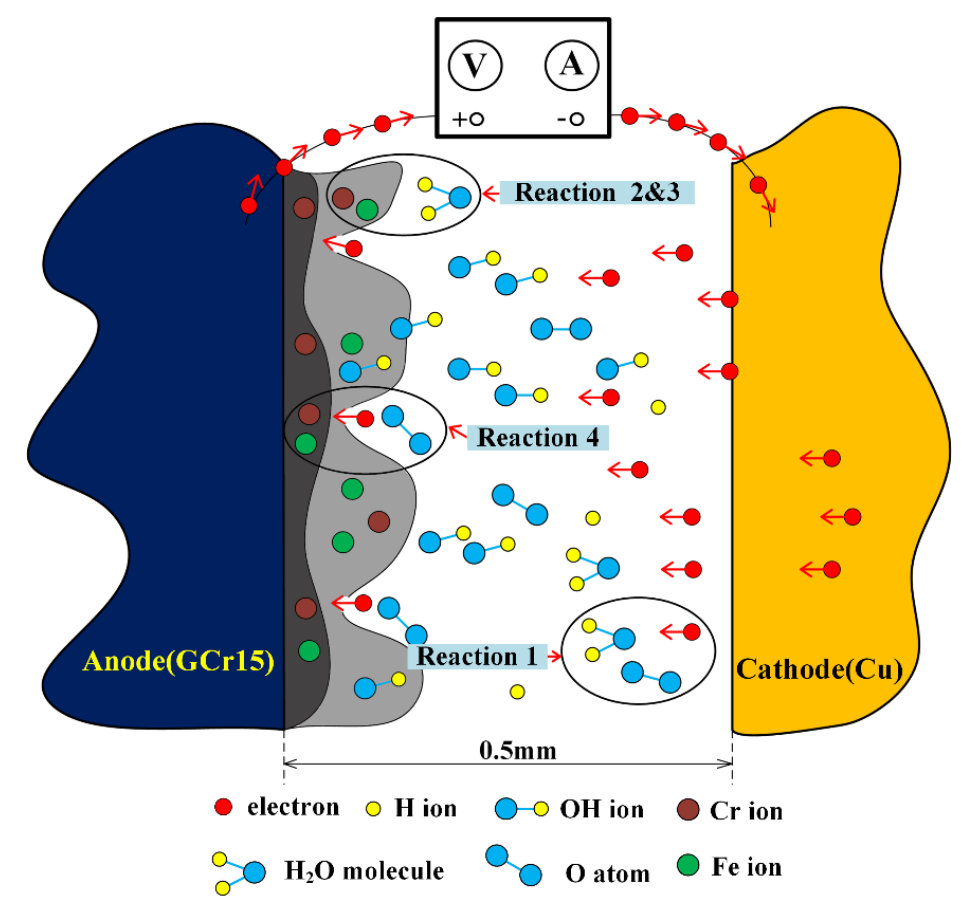

Fig. 6 Pattern of forming of passive film on GCr15 surface

Based on the phase-forming theory, the hydroxide and oxyhydroxide such as $\mathrm{FeOOH}$ and $\mathrm{CrOOH}$ in the form of $\mathrm{Fe}[\mathrm{II}]$ and $\mathrm{Cr}[\mathrm{II}]$ firstly appeared and formed the surface passive film due to hydration reactions like Reaction.1, 2, 3. Hydroxide accounted for the majority in surface layer. At the same time, oxygen was going through the surface layer of the passive film, forming rupture-like and micro-porous structures on the surface layer, because of strong electrochemical machining process. According to adsorption theory[43], oxidized $\mathrm{Fe}^{2+}$ and $\mathrm{Cr}^{2+}$ and free $\mathrm{Fe}^{3+}$ and $\mathrm{Cr}^{3+}$ formed dense oxide in the inner layer of passive film. $\mathrm{Cr}_{2} \mathrm{O}_{3}$ was generally considered to play a key role in the compactness and completeness of the passive film[44]. The micro/nanoscale binary rough structures that realized superhydrophobicity were formed due to compound effects on the same surface[45]. The passivation is actually a part of processing of polarization which was used for grain boundary etching and further controlling micro structures[23].

In this process, we could control damage degree of the surface layer that caused by forming process of the 
inner layer by adjusting electrochemical machining parameters, and further control the microstructures and wettability of mold steel GCr15 surface.

3.4 Durability of superhydrophobic surfaces

Under optimum ECM parameters $\left(i=5 \mathrm{~A} \cdot \mathrm{cm}^{-2}\right.$ and $\left.t=90 \mathrm{~s}\right)$, the samples still showed high superhydrophobicity with a water contact angle of $161.8^{\circ}$ after exposure to air for one year under normal ambient conditions [Fig. 7]. This indicates that the superhydrophobic surfaces fabricated via the ECM methods have good durability to the environment.
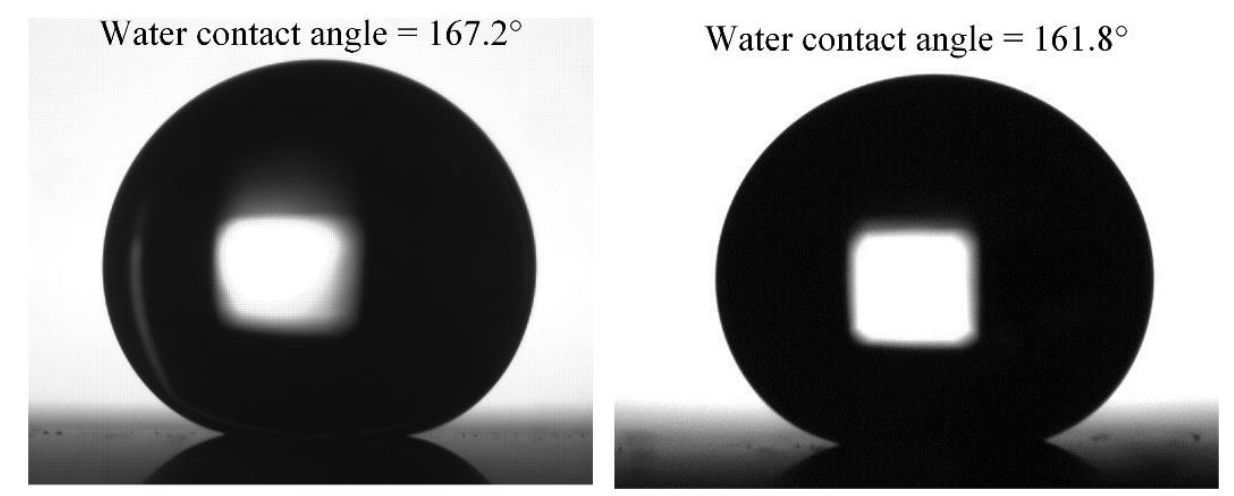

Fig. 7 The microscope images of the water droplets on original surface (left) and surface after storing one

$$
\text { year (right) }
$$

\section{Conclusions}

(1) We had developed a simple, low cost and environmentally friendly method to fabricate superhydrophobic surfaces on mold steel GCr15 substrate. The passive films that were composed of micro/nano binary rough structures were formed on the samples via electrochemical machining so that the superhydrophobic sample surfaces could be obtained after FAS modification. The water contact angles of the obtained sample surfaces were $167.2^{\circ}$, while the water rolling angles were only $4.4^{\circ}$.

(2) The passive films on GCr15 were compound films with two layers. The surface layer was composed of 
hydroxide and oxyhydroxide with the form of $\mathrm{Fe}[\mathrm{II}]$ and $\mathrm{Cr}[\mathrm{II}]$, and the inner layer was composed of $\mathrm{Fe}_{2} \mathrm{O}_{3}$ and $\mathrm{Cr}_{2} \mathrm{O}_{3}$.

(3) Based on the microstructures and chemical compositions investigated via SEM, XPS, XRD and FTIR, micro/nano binary rough structures including rugged plateau and rupture-like special structures and low surface energy modification were essential to fabricate superhydrophobic surfaces.

(4) The current density of electrochemical machining had great influence on the wettability. The superhydrophobicity could only be obtained while $i>3 \mathrm{~A} \cdot \mathrm{cm}^{-2}$. Additionally, processing time had little effect on surface wettability under $5 \mathrm{~A} \cdot \mathrm{cm}^{-2}$ proper current density, and superhydrophobic surfaces could be prepared within just a few seconds.

\section{Acknowledgement}

This project was financially supported by National Natural Science Foundation of China (NSFC, 51605078), Science Fund for Creative Research Groups of NSFC (51621064), the Doctoral Scientific Research Foundation of Liaoning Province (201601058) and the Fundamental Research Funds for the Central Universities (DUT17JC25). Y. Lu acknowledges the support from EPSRC project EP/N024915/1.

\section{References}

[1] A. Lafuma, D. Quéré, Superhydrophobic states, Nat. Mater. 2 (2003) 457-460.

[2] C. Li, Y. Zhang, J. Ju, F. Cheng, M. Liu, L. Jiang, Y. Yu, In situ fully light-driven switching of superhydrophobic adhesion, Adv. Funct. Mater. 22 (2012) 760-763.

[3] R. Blossey, Self-cleaning surfaces-virtual realities, Nat. Mater. 2 (2003) 301-306.

[4] Y. Lu, S. Sathasivam, J. Song, C. R. Crick, C. J. Carmalt, I. P. Parkin, Robust self-cleaning surfaces that function when 
exposed to either air or oil, Sci. 347 (2015) 1132-1135.

[5] L. Cao, A. K. Jones, V. K. Sikka, J. Wu, D. Gao, Anti-icing superhydrophobic coatings, Langmuir. 25 (2009) 1244412448.

[6] P. Guo, Y. Zheng, M. Wen, C. Song, Y. Lin, L. Jiang, Icephobic/Anti-Icing Properties of Micro/Nanostructured Surfaces, Adv. Funct. Mater. 24 (2012) 2642-2648.

[7] S. Srinivasan, J. A. Kleingartner, J. B. Gilbert, R. E. Cohen, A. J. B. Milne, G. H. McKinley, Sustainable drag reduction in turbulent Taylor-Couette flows by depositing sprayable superhydrophobic surfaces, Phys. Rev. Lett. 114 (2015) 014501.

[8] I. U. Vakarelski, N. A. Patankar, J. O. Marston, D. Y. Chan, S. T. Thoroddsen, Stabilization of Leidenfrost vapour layer by textured superhydrophobic surfaces, Nature 489 (2012) 274-277.

[9] P. Wang, D. Zhang, R. Qiu, Y. Wan, J. Wu, Green approach to fabrication of a super-hydrophobic film on copper and the consequent corrosion resistance, Corros. Sci. 80 (2014) 366-373.

[10] H. Jie, Q. Xu, L. Wei, Y. Min, Etching and heating treatment combined approach for superhydrophobic surface on brass substrates and the consequent corrosion resistance, Corros. Sci. 102(2016) 251-258.

[11] Y. Jang, W. T. Choi, C. T. Johnson, A. J. Garcia, P. M. Singh, V. Breedveld, D. W. Hess, J. A. Champion, Inhibition of Bacterial Adhesion on Nanotextured Stainless Steel 316L by Electrochemical Etching, ACS Biomater. Sci. Eng. 4 (2018) 9097.

[12] R. Du, X. Gao, Q. Feng, Q. Zhao, P. Li, S. Deng, L. Shi, J. Zhang, Microscopic dimensions engineering: stepwise manipulation of the surface wettability on 3d substrates for oil/water separation, Adv. Funct. Mater. 28 (2016) 936-942.

[13] W. Zhang, Z. Shi, F. Zhang, X. Liu, J. Jin, L. Liang, Superhydrophobic and superoleophilic PVDF membranes for effective separation of water-in-oil emulsions with high flux, Adv. Mater. 25 (2013) 2071-2076.

[14] H. Chen, P. Zhang, L. Zhang, H. Liu, Y. Jiang, D. Zhang, Z. Han, L. Jiang, Continuous directional water transport on the peristome surface of Nepenthes alata, Nature 532 (2016) 85-101.

[15] Y. Lu, S. Sathasivam, J. Song, F. Chen, W. Xu, C. J. Carmalt, I. P. Parkin, Creating superhydrophobic mild steel surfaces for water proofing and oil-water separation, J. Mater. Chem. A. 2 (2014) 11628-11634.

[16] B. H. Smith, S. Szyniszewski, J. F. Hajjar, B. W. Schafer, S. R. Arwade, Steel foam for structures: A review of applications, manufacturing and material properties, J. Constr. Steel. Res. 71 (2012) 1-10. 
[17] F. J. Shiou, H. S. Ciou, Ultra-precision surface finish of the hardened stainless mold steel using vibration-assisted ball polishing process, Int. J. Mach. Tools Manuf. 48 (2008) 721-732.

[18] L. J. Chen, M. Chen, H. D. Zhou, J. M. Chen, Preparation of super-hydrophobic surface on stainless steel, Appl. Surf. Sci. 255 (2008) 3459-3462.

[19] J. Tan, J. Hao, Z. An, C. Liu, Simple fabrication of superhydrophobic nickel surface on steel substrate via electrodeposition, Int. J. Electrochem. Sci. 12 (2017) 40-49.

[20] L. Li, V. Breedveld, D. W. Hess, Creation of superhydrophobic stainless steel surfaces by acid treatments and hydrophobic film deposition, ACS Appl. Mater. Inter. 4 (2012) 4549-4556.

[21] X. Gao, Z. Guo, Mechanical stability, corrosion resistance of superhydrophobic steel and repairable durability of its slippery surface, J. Colloid Interf. Sci. 512 (2018) 239-248.

[22] W. T. Choi, K. Oh, P. M. Singh, V. Breedveld, D. W. Hess, Wettability control of stainless steel surfaces via evolution of intrinsic grain structures, J. Mater. Sci. 51 (2016) 5196-5206.

[23] W. T. Choi, K. Oh, P. M. Singh, V. Breedveld, D. W. Hess, Hydrophobicity and Improved Localized Corrosion Resistance of Grain Boundary Etched Stainless Steel in Chloride-Containing Environment, J. Electrochem. Soc. 164 (2017) 61-65.

[24] B. Wu, M. Zhou, J. Li, X. Ye, G. Li, L. Cai, Superhydrophobic surfaces fabricated by microstructuring of stainless steel using a femtosecond laser, Appl. Surf. Sci. 256 (2009) 61-66.

[25] T. Singh, A. Dvivedi, Developments in electrochemical discharge machining: A review on electrochemical discharge machining, process variants and their hybrid methods, Int. J. Mach. Tools Manuf. 105 (2016) 1-13.

[26] T. Darmanin, E. T. de Givenchy, S. Amigoni, F. Guittard, Superhydrophobic surfaces by electrochemical processes, Adv. Mater. 25 (2013) 1378-1394.

[27] J. Sun, F. Zhang, J. Song, L. Wang, Q. Qu, Y. Lu, I. P. Parkin, Electrochemical fabrication of superhydrophobic Zn surfaces, Appl. Surf. Sci. 315 (2014) 346-352.

[28] W. Xu, J. Song, J. Sun, Y. Lu, Z. Yu, Rapid fabrication of large-area, corrosion-resistant superhydrophobic Mg alloy surfaces, ACS Appl. Mater. Inter. 3 (2011) 4404-4414.

[29] B. Jiang, S. Lan, K. Wilt, J. Ni, Modeling and experimental investigation of gas film in micro-electrochemical discharge 
machining process, Int. J. Mach. Tools Manuf. 90 (2015) 8-15.

[30] K. Y. Kuo, K. L. Wu, C. K. Yang, B. H. Yan, Wire electrochemical discharge machining (WECDM) of quartz glass with titrated electrolyte flow, Int. J. Mach. Tools Manuf. 72 (2013) 50-57.

[31] T. S. L. Wijesinghe, D. J. Blackwood, Characterisation of passive films on 300 series stainless steels, Appl. Surf. Sci. 253 (2006) 1006-1009.

[32] Y. Zeng, Y. Zhou, L. Kong, T. Zhou, G. Shi, A novel composite of $\mathrm{SiO}_{2}$-coated graphene oxide and molecularly imprinted polymers for electrochemical sensing dopamine, Biosens. Bioelectron. 45 (2013) 25-33.

[33] J. Song, D. Zhao, Z. Han, W. Xu, Y. Lu, X. Liu, B. Liu, C. J. Carmalt, X. Deng, I. P. Parkin, Super-Robust Superhydrophobic Concrete, J. Mater. Chem. A. 5 (2017) 14542-14550.

[34] A. Checco, B. M. Ocko, A. Rahman, C. T. Black, M. Tasinkevych, A. Giacomello, S. Dietrich, Collapse and reversibility of the superhydrophobic state on nanotextured surfaces, Phys. Rev. Lett. 112 (2014) 216101.

[35] R. N. Wenzel, Resistance of solid surfaces to wetting by water, Ind. Eng. Chem. Res. 28 (1936) 988-994.

[36] Z. Xue, S. Wang, L. Lin, L. Chen, M. Liu, L. Feng, L. Jiang, A novel superhydrophilic and underwater superoleophobic hydrogel-coated mesh for oil/water separation, Adv. Funct. Mater. 23 (2011) 4270-4273.

[37] A. B. D. Cassie, S. Baxter, Wettability of porous surfaces, Trans. Faraday Soc. 40 (1944) 546-551.

[38] N. Zhao, J. Xu, Q. Xie, L. Weng, X. Guo, X. Zhang, L. Shi, Fabrication of Biomimetic Superhydrophobic Coating with a Micro-Nano-Binary Structure, Macromol. Rapid Comm. 26 (2005) 1075-1080.

[39] F. Cao, G. L. Song, A. Atrens, Corrosion and passivation of magnesium alloys, Corros. Sci. 111 (2016) 835-845.

[40] U. Phatak, S. Bukkapatnam, Z. Kong, R. Komanduri, Sensor-based modeling of slurry chemistry effects on the material removal rate (MRR) in copper-CMP process, Int. J. Mach. Tools Manuf. 49 (2009) 171-181.

[41] A. Kocijan, Č. Donik, M. Jenko, Electrochemical and XPS studies of the passive film formed on stainless steels in borate buffer and chloride solutions, Corros. Sci. 49 (2007) 2083-2098.

[42] J. Kruger, The nature of the passive film on iron and ferrous alloys, Corros. Sci. 29 (1989) 149-162.

[43] M. G. S. Ferreira, J. L. Dawson, Electrochemical studies of the passive film on 316 stainless steel in chloride media, J. Eletrochem. Soc. 132 (1985) 760-765. 
[44] E. McCafferty, M. K. Bernett, J. S. Murday, An XPS study of passive film formation on iron in chromate solutions, Corros. Sci. 28 (1988) 559-576.

[45] A. Nazarov, V. Vivier, D. Thierry, F. Vucko, B. Tribollet, Effect of Mechanical Stress on the Properties of Steel Surfaces: Scanning Kelvin Probe and Local Electrochemical Impedance Study, J. Eletrochem. Soc. 164 (2017) C66-C74. 